\title{
The Importance of Psychological Assessment and Support in Patients Suffering from Cardiovascular Disease or Undergoing Cardiac Treatment
}

\author{
Daniel Peter Stoll ${ }^{1}$, Noemi Csaszar ${ }^{2 *}$, Henrik Szoke ${ }^{3}$ and Petra Bagdi ${ }^{4}$
}

${ }^{1}$ Psychologist, Deputy-head of Psychotherapy Department, National Centre for Spinal Disorders, Budapest, Hungary

${ }^{2}$ Psychotherapist, Head of Psychotherapy Department, National Centre for Spinal Disorders, Budapest, Hungary

${ }^{3}$ Specialist in Pediatrics, National Centre for Spinal Disorders, Budapest, Hungary

${ }^{4}$ Psychologist, National Centre for Spinal Disorders, Budapest, Hungary

"Corresponding author: Császár-Nagy Noémi, Head of the Education Board of the Hungarian Association of Hypnosis (H.A.H), Clinical Psychologist, Supervisor Hypnotherapist, Psychotherapist, Head of Psychotherapy Department and Psychosomatic Out-Patient Department at the National Center for Spinal Disorders in Budapest, 1126 Királyhágó Street 1, Budapest, Hungary, Tel: +36 30754 8427; E-mail: noemi.csaszar@areus.hu

Received on: April 16, 2014, Accepted on: May 31, 2014, Published on: June 07, 2014

Copyright: (C) 2014 Noémi CN et al. This is an open-access article distributed under the terms of the Creative Commons Attribution License, which permits unrestricted use, distribution, and reproduction in any medium, provided the original author and source are credited.

\begin{abstract}
Psychosocial factors play an undoubtedly important role in the development of cardiovascular diseases and can also highly affect efficacy and outcome of cardiac treatment or the success of rehabilitation. These factors are proven to have a major role in patient evaluation in two ways: (1) risk factors are important in establishing prognosis and/or as (2) indicators of need for further specific psychological interventions.

According to the literature available: depression, severe anxiety and other psychosocial characteristics are considered to be risk factors. These factors include low socio-economic status, chronic family or work related stress, social isolation or lack of support, negative emotions, affective dysregulation and also negative personality patterns or hostility. Identifying and examining these factors have great importance in multidisciplinary patient care. It is important to highlight the chances of adverse outcome and provide clinical solutions since many of the risk factors are treatable psychological conditions.
\end{abstract}

Keywords: Psychosocial Risk; Cardiovascular Disorder; Adverse Outcome; Psychological Intervention

\section{Introduction}

There is a growing field of knowledge supporting the fact that psychological factors can affect the development and the continuity of chronic diseases such as chronic lower back pain (CLBP) and cardiovascular diseases (CVD) [1-6]. Some of these "cardio toxins" have direct effect on physical functions and some have indirect influence on lifestyle behaviors leading to unhealthy habits (Table 1) [6-8].

The most significant psychosocial factors are depression, anxiety, stress, anger and social isolation [8-20]. Individual and combined psychosocial factors show connection with the coronary artery disease, the onset of heart attack, the length of post-heart attack hospitalization and post-heart attack survival [4,22-25].

The presences of psychosocial risks have an impact not only on the development but also on the chances of recovery and of mortality after a cardiac event. It is associated with the occurrence of adverse outcome in patients with established coronary artery disease [26]. Thus psychological assessment of the cardiac patient can play an important role in treatment planning, providing confirmation in medical decision-making and helps to predict the indication for treatment modalities and long-term outcomes of medical treatments.

\section{Possible physiological pathways}

Psychological distress affects the neurohormonal regulation promoting chronic changes in physical functioning (Table 1) [6-8].
The stress-response is characterized by release of catecholamines and corticosteroids, increased heart rate, autonomic cardiac functioning, and blood pressure, also changes in processes relevant to clotting processes, such as coronary vasoconstriction, platelet aggregation, or plaque rupture. Stress induced autonomic nervous system activation might also lead to the occurrence (or reoccurrence) of cardiac event by artherosclerosis or the dysfunction of cells in the coronary artery lining, or by directly triggering arrhythmias through alterations of neural transmission [27].

\begin{tabular}{|l|l|}
\hline $\begin{array}{l}\text { Acute stress } \\
\text { (laboratory induced or } \\
\text { traumatic life-event) }\end{array}$ & $\begin{array}{l}\text { Increased sympathetic nervous system functioning } \\
\text { and hypothalamic pituitary adrenal axis activity, } \\
\text { increased blood pressure heart rate and } \\
\text { hypertension, heightened interleukin 6 level }\end{array}$ \\
\hline $\begin{array}{l}\text { Chronic stress } \\
\text { (work stress, marital } \\
\text { strain, life adversity, etc) }\end{array}$ & $\begin{array}{l}\text { Increased sympathetic nervous system functioning } \\
\text { and hypothalamic pituitary adrenal axis activity, } \\
\text { increased ambulatory blood pressure, heart rate, } \\
\text { inflammation and hypertension }\end{array}$ \\
\hline $\begin{array}{l}\text { Mood state } \\
\text { (depression, anxiety, etc) }\end{array}$ & $\begin{array}{l}\text { Increased inflammation, platelet functioning, } \\
\text { autonomic nervous system dysregulation, } \\
\text { hypothalamic pituitary adrenal axis dysregulation }\end{array}$ \\
\hline
\end{tabular}

Table 1: Effects of psychosocial factors and health behaviors on cardiovascular functioning

There are great differences in how the same level of stress exposure can affect the individual physiological functioning. For example the same chronic stressors can lead to sustained hypertension in some individuals but not in others. This phenomenon can be explained by genetic predisposition, personality and coping style as well as 
Page 2 of 5

environmental differences affecting the adaptation to certain distresses [28].

\section{The focus of psychological interventions}

There is a wide range of psychosocial risk factors that can be taken into consideration during the assessment of cardiac patients. The three main areas of psychological issues associated with CVD are: (A) Evaluating cardiac patients and identifying the existing risk factors; (B) Facilitating health promoting behavioral changes and adherence to medical treatment; (C) Interventions to treat psychological risk factors that influence the onset and progression of CVDs [29-32].

\section{Conceptualizing psychosocial risk}

There seems to be from strong to moderate evidence supporting the importance of psychological factors, but certain doubts about the role of psychosocial risk still exist concerning the scientific validity and clinical relevance of these findings [33]. The uncertainty arises from methodological inconsistencies, and from the definition, measurement and interpretation of various psychosocial measures (negative effects, depression, stress, anger etc.)[34]. Different studies may also use different psychometric tools for the measurement of psychosocial risk factors [35]. For instance the scope of one depression scale can highly differ from another psychometric tool, providing different results leading to contradiction in literature [32]. It is advised to use wellvalidated self-report questionnaires and structured interviews as well to assess psychosocial characteristics and well-validated cutoff scores and diagnostic criteria to define affecting factors [36].

\section{Depression}

Research evidence shows that the chronic depressive mood has a significant role in the progression of a heart disease. It has both behavioral and pathophysiological pathways as well [9,37]. The pathophysiological effects include a change in the cortisol hormone level, neuroendocrine and endothelial dysfunction, disturbance in autonomic cardiac functioning, inflammation and enhanced platelet functioning $[6,8,15,36]$. Depression can also be linked to poor health behavior such as smoking, obesity, poor compliance and adherence $[6,37]$. It also effects the participation in cardiac rehabilitation such as intention to participate and future dropouts from program and its outcome [38].

Depression is also a strong predictor for adverse short- and longterm clinical outcomes in patients with CVD [6,10,39]. A recent systematic literature review (analyzing 52 individual studies and 4 meta-analyses) showed strong connection between depression and adverse clinical outcomes [36].

According to Nakamura and colleagues depression can be the strongest independent risk factor for CVD related adverse outcomes including arrhythmias, angina, prolonged disability, re-hospitalization and increased mortality [38]. Studies suggest that somatic-affective, but not cognitive factors of depressive symptoms are responsible for the increased risk $[40,41]$.

According to prospective epidemiological studies hopelessness as an aspect of depression can even double the risk of CAD. Also this specific symptom has been linked to sudden death both in observational studies and animal models [Table 2] [6].

\begin{tabular}{|c|c|c|}
\hline \multirow{8}{*}{\multicolumn{2}{|c|}{$\begin{array}{l}\text { Somatic } \\
\text { depression }\end{array}$}} & Body image change \\
\hline & & Work difficulty \\
\hline & & Insomnia \\
\hline & & Fatigability \\
\hline & & Loss of appetite \\
\hline & & Weight loss \\
\hline & & Somatic preoccupation \\
\hline & & Loss of libido \\
\hline
\end{tabular}

Table 2: Somatic symptoms of depression

\section{Anxiety}

There are several ways in which anxiety affects heart health and plays a role in the progression of CVDs. On one hand it can be linked to ventricular arrhythmias, and on the other hand research supports the connection with reduced heart rate variability [42]. Anxiety is also connected to negative lifestyle behaviors such as poor dietary habits, smoking etc., but the causal relationship is hard to establish between psychological and behavioral factors [43].

In a longitudinal research 180 patients undergoing cardiac surgery were followed for ten years. Anxiety, depression and the number and reason for re-hospitalizations were assessed yearly. Research results shows that preoperative anxiety increases the risk for long-term mortality after cardiac surgery especially in patients with low education status and social support $[44,45]$.

\section{Psychological distress}

Stress is one of the most commonly mentioned factors that contribute to poor cardiovascular health, although there are several aspects of this phenomenon [15].

It is believed that chronic stressors (work related, environmental and subacute accumulated life stress) have direct impact on the physiological stress response system and it is also associated with poor lifestyle behaviors that contribute to coronary artery disease $[46,47]$. The factors provoking stress response are highly diverse from socioeconomic status, marital conflict, job dissatisfaction and insecurity, gender discrimination, life-altering event to psychiatric disorders [48]. There are several studies showing that psychological distress can contribute to increased risk of death due to cardiovascular disease $[49,50]$.

\section{Aggression and hostility}

It is one of the earliest and most controversial risk factor which emerged from the Type A personality concept associated with poor hearth health [6,51]. According to Davidson and Mostofsky, we can distinguish between beneficial and detrimental types of anger in terms of adverse outcome, but self-report assessment tools are inappropriate for differentiation. Lately research evidence is supporting that only the hostile component of anger is truly harmful to cardiovascular health, moreover moderate anger expression can be a protective factor against future CVD events [4]. 
From a behavioral aspect this kind of affective state can be associated with problematic lifestyle behaviors such as poor diet, obesity, and alcoholism, smoking and social isolation [52].

\section{Social bonds}

The lack of social support is also an associated risk factor for CVD. The phenomenon is poorly conceptualized, which causes a great interference among study results. It can be examined from different points of views, since it is about more than the physical presence of people. Social deprivation effects the neuroendocrine regulation by the changes caused in the body's stress response $[6,15]$.

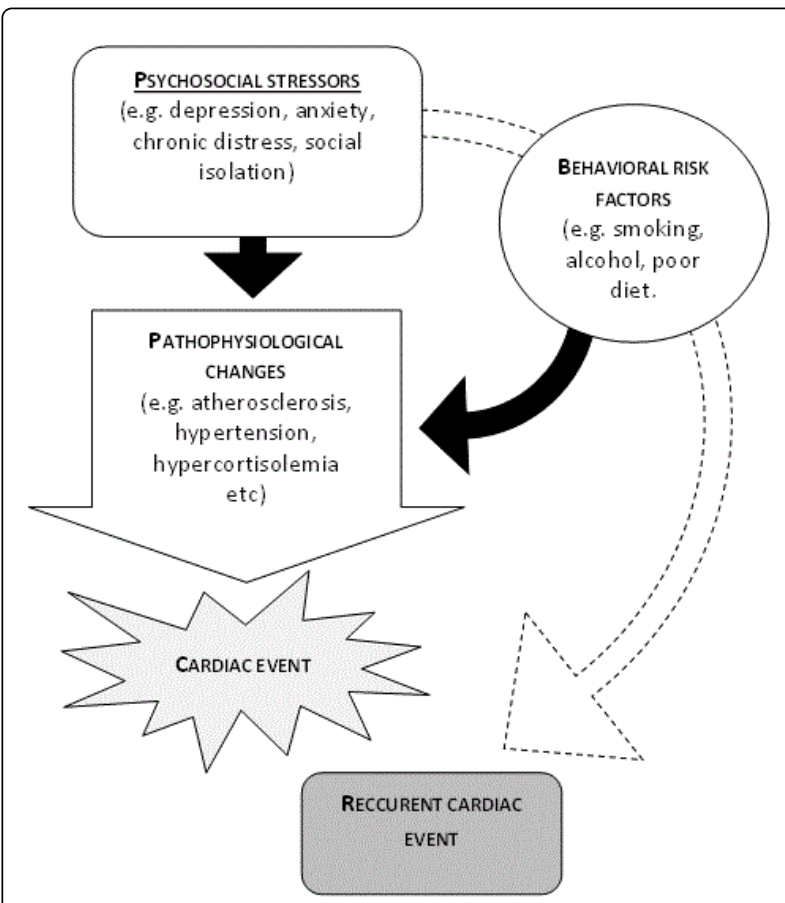

Figure 1: Potential pathways of psychosocial stressors affecting development and progression of CVD

Not only does it contribute to the development of specific diseases but can highly affect survival rates after cardiac events. The absence of social bonds and relationships has been found a three times greater risk for mortality in three years period after heart attack [53,54]. Many aspects of social isolation, like the perceived quality of social network, feeling of loneliness and the physical absence of others can have a negative effect on cardiovascular health [6,18-20]. These factors can contribute to the development and progression of coronary disease and to the raised chances of having a second MI and poor recovery after cardiac event [55].

Distress induced by the CVD does not only affect the patient, but his/her social connections as well. The degree of depression or anxiety for the partner is at least as great as the distress of the patient, thus the disease have an overall effect on social relationships [56].

\section{Psychological assessment and interventions before cardiac surgery}

Because of the previously shown risk factors psychological screening can be extremely useful not only in primary prevention, but also in predicting the risk of prolonged hospitalization or other adverse short- or long-term outcomes. Evaluation, psychoeducation and psychological support may reduce adverse effects leading to a more efficient treatment and more cost-effective care [57].

One author addresses the timing of psychometric testing, because general distress caused by the cardiac event or by hospitalization can distort the results. Nakamura and colleagues propose that psychological screening can be most useful at discharge, because lasting distress or psychiatric condition is more stable than during other periods of hospital stay. Also, evidence exists emphasizing the efficacy of multidisciplinary cardiovascular rehabilitation where psychological interventions play an important role [58]. Some findings suggest that the patient and his/her partner should be conceptualized as a "dyadic unit" and therefore both of them should be involved in psychological care [56].

Most of the psychosocial risk factors are treatable psychological conditions [1]. Thus psychological interventions can be used to prevent adverse outcomes. According to a systematic review psychological interventions for cardiac patients have the potential to improve health-related quality of life, anxiety, blood pressure, knowledge and satisfaction with care [56]. These interventions can even result in improved quality of life and also improved mortality $[59,60]$.

If needed, pharmacological treatment can be taken into consideration, which can be effective in reducing the somatic/affective symptoms of depression in order to increase the potential to affect the cardiac prognosis [41]. However some medications have adverse cardiovascular effects. Tricyclic agents and monoamine oxidase inhibitors should be used more cautiously in patients with CAD, also some of the selective serotonin reuptake inhibitors (SSRIs) may interact with certain cardiovascular drugs [61]. Still, SSRIs are the most commonly used products according to their safety profile regarding the cardiovascular system [41,62]. It is important that the beneficial effects of SSRIs appear only after 2 weeks' time on average, thus they won't ease the depressive symptoms in the preoperative period. In some cases it may be desirable to postpone surgery until depression responds to treatment, if the patient's medical condition is stable enough [57].

\section{Conclusion}

In many areas psychology has found its unique role integrating its knowledge and practice into conventional medicine. Nowadays psychological factors are considered as strong and independent risk factors for chronic disease, but usually are not recognized in the clinical practice [26]. There are existing models for psychological patient assessment in spinal care, and for implantable devices [1,63-65]. In the field of cardiology however, evidence is controversial regarding the role of psychological interventions. Components of disease etiology are closely related, thus independent risk factors are hard to investigate. Distress experienced by the cardiac event or before the surgery leads to distorted measures of psychological variables. From a methodological perspective multifactorial psychosocial correlates of long-term outcomes should be examined weeks after the cardiac event. Personalized psychological interventions are problematic to compare to individual etiological constructs.

For better clinical relevance psychosocial, behavioral and medical risk factors can be assigned a point value based on the strength of the 
research relevance, thus all the risk ratings could be administered in a clinical algorithm.

Clinical practice should be tending towards multidisciplinary care models and recognize the evidence of the benefits of comprehensive patient care. It can result in a decrease of adverse outcomes, decrease of treatment expenses, improvements in quality of life and in decrease of disability $[26,58,66]$.

\section{References}

1. Bruns D, Disorbio JM (2009) Assessment of biopsychosocial risk factors for medical treatment: a collaborative approach. J Clin Psychol Med Settings 16: 127-147.

2. Melloh M, Elfering A, Egli Presland C, Röder C, Hendrick P, et al. (2011) Predicting the transition from acute to persistent low back pain. Occup Med (Lond) 61: 127-131.

3. Ramond A, Bouton C, Richard I, Roquelaure Y, Baufreton C, et al. (2011) Psychosocial risk factors for chronic low back pain in primary care--a systematic review. Fam Pract 28: 12-21.

4. Nakamura S, Kato K, Yoshida A, Fukuma N, Okumura Y, et al. (2013) Prognostic value of depression, anxiety, and anger in hospitalized cardiovascular disease patients for predicting adverse cardiac outcomes. The American journal of cardiology 111: 1432-1436.

5. Glozier N, Tofler GH, Colquhoun DM, Bunker SJ, Clarke DM, et al. (2013) Psychosocial risk factors for coronary heart disease. Med J Aust 199: 179-180.

6. Rozanski A, Blumenthal JA, Kaplan J (1999) Impact of psychologica factors on the pathogenesis of cardiovascular disease and implications for therapy. Circulation 99: 2192-2217.

7. Hemingway H, Marmot M (1999) Evidence based cardiology: psychosocial factors in the aetiology and prognosis of coronary heart disease. Systematic review of prospective cohort studies. BMJ 318: 1460-1467.

8. Musselman DL, Tomer A, Manatunga AK, Knight BT, Porter MR, et al. (1996) Exaggerated platelet reactivity in major depression. Am J Psychiatry 153: 1313-1317.

9. Lett HS, Blumenthal JA, Babyak MA, Sherwood A, Strauman T, et al. (2004) Depression as a risk factor for coronary artery disease: evidence, mechanisms, and treatment. Psychosom Med 66: 305-315.

10. Nicholson A, Kuper H, Hemingway H (2006) Depression as an aetiologic and prognostic factor in coronary heart disease: a meta-analysis of 6362 events among 146538 participants in 54 observational studies. Eur Heart J 27: 2763-2774.

11. Chen W, Woods SL, Wilkie DJ, Puntillo KA (2005) Gender differences in symptom experiences of patients with acute coronary syndromes. J Pain Symptom Manage 30: 553-562.

12. Suls J, Bunde J (2005) Anger, anxiety, and depression as risk factors for cardiovascular disease: the problems and implications of overlapping affective dispositions. Psychol Bull 131: 260-300.

13. Roest AM, Martens EJ, Denollet J, de Jonge P (2010) Prognostic association of anxiety post myocardial infarction with mortality and new cardiac events: a meta-analysis. Psychosom Med 72: 563-569.

14. Bunker SJ, Colquhoun DM, Esler MD, Hickie IB, Hunt D, et al. (2003) "Stress" and coronary heart disease: psychosocial risk factors. Med J Aust 178: 272-276.

15. Sapolsky RM (2004) Why Zebras Don't Get Ulcers: The Acclaimed Guide to Stress, Stress-Related Disease, and Coping. New York.

16. McDermott MR, Ramsay JM, Bray C (2001) Components of the Angerhostility Complex as Risk Factors for Coronary Artery Disease Severity: A Multi-measure Study. J Health Psychol 6: 309-319.

17. Donker FJ, Breteler MH, van der Staak CP (2000) Assessment of hostility in patients with coronary heart disease. J Pers Assess 75: 158-177.

18. Tennant C (1999) Life stress, social support and coronary heart disease. Aust N Z J Psychiatry 33: 636-641.
19. Kivimäki M, Virtanen M, Vartia M, Elovainio M, Vahtera J, et al. (2003) Workplace bullying and the risk of cardiovascular disease and depression. Occup Environ Med 60: 779-783.

20. Barth J, Schumacher M, Herrmann-Lingen C (2004) Depression as a risk factor for mortality in patients with coronary heart disease: a metaanalysis. Psychosom Med 66: 802-813.

21. Boyle SH, Michalek JE, Suarez EC (2006) Covariation of psychological attributes and incident coronary heart disease in U.S. Air Force veterans of the Vietnam war. Psychosom Med 68: 844-850.

22. Mittleman MA, Maclure M, Sherwood JB, Mulry RP, Tofler GH, et al. (1995) Triggering of acute myocardial infarction onset by episodes of anger. Determinants of Myocardial Infarction Onset Study Investigators. Circulation 92: 1720-1725.

23. Karademas EC (2010) Illness cognitions as a pathway between religiousness and subjective health in chronic cardiac patients. J Health Psychol 15: 239-247.

24. Thomas SA, Friedmann E, Wimbush F, Schron E (1997) Psychological factors and survival in the cardiac arrhythmia suppression trial (CAST): a reexamination. Am J Crit Care 6: 116-126.

25. Friedmann E, Thomas SA, Liu F, Morton PG, Chapa D, et al. (2006) Relationship of depression, anxiety, and social isolation to chronic heart failure outpatient mortality. Am Heart J 152: 940.

26. Khayyam-Nekouei Z, Neshatdoost H, Yousefy A, Sadeghi M, Manshaee G (2013) Psychological factors and coronary heart disease. ARYA Atheroscler 9: 102-111.

27. Krantz DS, McCeney MK (2002) Effects of psychological and social factors on organic disease: a critical assessment of research on coronary heart disease. Annu Rev Psychol 53: 341-369.

28. Hamer M (2009) Psychological Risk Factors in the Development of Hypertension In: Sher, L. (Ed) Psychological Factors and Cardiovascular Disorders.Nova Science Publishers, USA.

29. Davidson, KW, Kupfer DJ, Bigger JT, Califf RM, Carney RM, et al. (2006) Assessment and treatment of depression in patients with cardiovascular disease: National Heart, Lung and Blood Institute working group report. Annals of Behavioral Medicine, 32:121-126.

30. Dickens C, Cherrington A, McGowan L (2012) Depression and healthrelated quality of life in people with coronary heart disease: a systematic review. Eur J Cardiovasc Nurs 11: 265-275.

31. (2008) Comprehensive Handbook of Clinical Health Psychology. Boyer BA, Paharia M I (Eds)Wiley J John Wiley \& Sons, USA.

32. Nunes EV, Frank KA, Kornfeld DS (1987) Psychologic treatment for the type A behavior pattern and for coronary heart disease: a meta-analysis of the literature. Psychosom Med 49: 159-173.

33. Violanti JM, Andrew ME, Burchfiel CM, Hartley TA, McCanlies E (2009) Biosocial Synergy: Stress, Cardiovascular Disease, and High Risk Populations In: Sher L (Ed) Psychological Factors and Cardiovascular Disorders, Nova Science Publishers, USA.

34. Scheidt S (2000) The current status of heart-mind relationships. J Psychosom Res 48: 317-320.

35. Krantz DS, Sheps DS, Carney RM, Natelson BH (2000) Effects of mental stress in patients with coronary artery disease: evidence and clinical implications. JAMA 283: 1800-1802.

36. Lichtman JH, Froelicher ES, Blumenthal JA, Carney RM, Doering LV, et al. (2014) Depression as a risk factor for poor prognosis among patients with acute coronary syndrome: systematic review and recommendations: a scientific statement from the American Heart Association. Circulation, 129: $1350-1369$.

37. Ziegelstein RC, Bush DE, Fauerbach JA (1998) Depression, adherence behavior, and coronary disease outcomes. Arch Intern Med 158: 808-809.

38. Shen BJ, Wachowiak PS, Brooks LG (2005) Psychosocial factors and assessment in cardiac rehabilitation. Eura Medicophys 41: 75-91.

39. Whooley MA, de Jonge P, Vittinghoff E, Otte C, Moos R, et al. (2008) Depressive symptoms, health behaviors, and risk of cardiovascular events in patients with coronary heart disease. JAMA 300: 2379-2388. 
Citation: Stoll DP, Csaszar N, Szoke H, Bagdi P (2014) The Importance of Psychological Assessment and Support in Patients Suffering from Cardiovascular Disease or Undergoing Cardiac Treatment. J Cardiovasc Dis Diagn 2: 161. doi:10.4172/2329-9517.1000161

Page 5 of 5

40. Bekke-Hansen S, Trockel M, Burg MM, Taylor CB. (2012) Depressive symptom dimensions and cardiac prognosis following myocardial infarction: results from the ENRICHD clinical trial. Psychological Medicine 42: 51-60

41. de Jonge P, Ormel J, van den Brink RH, van Melle JP, Spijkerman TA, et al. (2006) Symptom dimensions of depression following myocardial infarction and their relationship with somatic health status and cardiovascular prognosis. The American journal of psychiatry 163: 138-144.

42. Kawachi I, Sparrow D, Vokonas PS, Weiss ST (1995) Decreased heart rate variability in men with phobic anxiety (data from the Normative Aging Study). Am J Cardiol 75: 882-885.

43. Morrell H, Cohen L (2006) Cigarette Smoking, Anxiety, and Depression. Journal of Psychopathology and Behavioral Assessment 28: 283-297.

44. Székely A, Balog P, Benkö E, Breuer T, Székely J, et al. (2007) Anxiety predicts mortality and morbidity after coronary artery and valve surgery--a 4-year follow-up study. Psychosom Med 69: 625-631.

45. Cserép Z, Losoncz E, Balog P, Szili-Török T, Husz A, et al. (2012) The impact of preoperative anxiety and education level on long-term mortality after cardiac surgery. J Cardiothorac Surg 7: 86.

46. Kemeny M (2003) The psychobiology of stress: Current Directions in Psychological Science 12: 124-129.

47. Hamidreza Roohafza, Masoumeh Sadeghi, Nizal Sarraf-Zadegan, Abdolmehdi Baghaei, Roya Kelishadi, et al. (2007) Relation between stress and other life style factors. Stress \& Health 23: 23-29.

48. Pan A, Rexrode KM (2012) Taking psychological well-being to heart. CMAJ 184: 1453-1454.

49. Hamer M, Kivimaki M, Stamatakis E, Batty GD (2012) Psychological distress as a risk factor for death from cerebrovascular disease. CMAJ 184: 1461-1466.

50. May M, McCarron P, Stansfeld S, Ben-Shlomo Y, Gallacher J, et al. (2002) Does psychological distress predict the risk of ischemic stroke and transient ischemic attack? The Caerphilly Study. Stroke 33: 7-12.

51. Davidson KW, Mostofsky E (2010) Anger expression and risk of coronary heart disease: evidence from the Nova Scotia Health Survey. Am Heart J 159: 199-206.

52. Everson SA, Kauhanen J, Kaplan GA, Goldberg DE, Julkunen J, et al (1997) Hostility and increased risk of mortality and acute myocardial infarction: the mediating role of behavioral risk factors. Am J Epidemiol 146: $142-152$.

53. Arthur HM (2006) Depression, isolation, social support, and cardiovascular disease in older adults. J Cardiovasc Nurs 21: S2-7.
54. [No authors listed] (2007) Making connections good for the heart and soul. Loneliness takes a toll on the heart; building a social network can strengthen it. Harv Heart Lett 17: 5.

55. Elizur Y, Hirsh E. (1999) Psychosocial adjustment and mental health two months after coronary artery bypass surgery: a multisystemic analysis of patients' resources. Journal of Behavioral Medicine, 22: 157-177.

56. Jane Reid, Chantal F. Ski, David R. Thompson (2013) Psychological interventions for patients with coronary heart disease and their partners: a systematic review. PloS one, 8: 73459.

57. Pignay-Demaria V, Lespérance F, Demaria RG, Frasure-Smith N, Perrault LP (2003) Depression and anxiety and outcomes of coronary artery bypass surgery. Ann Thorac Surg 75: 314-321.

58. Wong WP, Feng J, Pwee KH, Lim J (2012) A systematic review of economic evaluations of cardiac rehabilitation. BMC Health Serv Res 12: 243.

59. Klein DM, Turvey CL, Pies CJ (2007) Relationship of coping styles with quality of life and depressive symptoms in older heart failure patients. J Aging Health 19: 22-38.

60. Martire LM, Lustig AP, Schulz R, Miller GE, Helgeson VS (2004) Is it beneficial to involve a family member? A meta-analysis of psychosocial interventions for chronic illness. Health Psychol 23: 599-611.

61. Lespérance F, Frasure-Smith N (2000) Depression in patients with cardiac disease: a practical review. J Psychosom Res 48: 379-391.

62. Roose SP, Laghrissi-Thode F, Kennedy JS, Nelson JC, Bigger JT Jr, et al. (1998) Comparison of paroxetine and nortriptyline in depressed patients with ischemic heart disease. JAMA 279: 287-291.

63. Heckler DR, Gatchel RJ, Lou L, Whitworth T, Bernstein D, et al. (2007) Presurgical Behavioral Medicine Evaluation (PBME) for implantable devices for pain management: a 1-year prospective study. Pain Pract 7: 110-122.

64. Celestin J, Edwards RR, Jamison RN (2009) Pretreatment psychosocial variables as predictors of outcomes following lumbar surgery and spinal cord stimulation: a systematic review and literature synthesis. Pain Medicine 10: 639-653.

65. Block AR, Gatchel RJ, Deardorff WW, Guyer RD (2003) The Psychology of Spine Surgery. American Psychological Association, Washington, DC.

66. Vingerhoets G, de Soete G, Jannes C (1995) Subjective complaints versus neuropsychological test performance after cardiopulmonary bypass. J Psychosom Res 39: 843-853. 